existing university system. The danger lies in the diversion of a large proportion of already inadequate resources to the duplication, in an entirely different situation, of a type of education which American educationists consider to be already outdated and which they are trying to bring into line with the more conventional type of university. If a technological institute were started de novo in Britain to-morrow, it could have no decisive impact upon British industrial structure and output for a quarter of a century at least. In the meantime, the attempt at its establishment would have fatally slowed down the progress of universities and technical colleges alike.

Nor is there sure evidence that such an institution would have the decisive effect its advocates claim. The American senior technological institutes came into existence during a period of expanding economy on a newish continent in a different world. An increasing section of educated American opinion is beginning to suspect they are not so well suited to the stage the country has reached to-day.

In the United States, too, there are no institutions which skim off the cream of national youth with such skill and in such quantity in proportion to total population as Oxford and Cambridge have in the past half-century in Great Britain. This is probably the greatest single obstacle to the solution of the United Kingdom problem of diverting a reasonable proportion of the flower of the nation's educated manhood into engineering development and design-the solving of which is the main objective of the advocates of an English "M.I.T.". The pick of our youth will gravitate to Oxford and Cambridge at the undergraduate stage for a generation to come, and it is inconceivable that these particular universities will allow of the development within their boundaries of great postgraduate applied science schools. The only solution of this dilemma is the development and full exploitation of the graduate school of specialist engineering in the existing civic universities and the colleges of technology.

Sir Raymond also discussed the place of the public school in the education of the engineer. Analysis of the schoolboy entry into the departments of mechanical and civil engineering of the University of Birmingham for the period 1938-51 showed that the percentage of the grammar school entry obtaining first-class honours was nearly double the percentage of the public school entry and nearly three times that of the other secondary schools. Sir Raymond believes that the civic universities do not receive a fair sample of public school men, and that the channelling of brains and character to the public schools must aggravate the already difficult problem of producing sufficient engineers of such quality of mind and personality as will enable them to make their way on to the directorates of the great industrial concerns and to see that the best possible use is made of the genius for invention and design that the nation unquestionably possesses. In the present situation too great a proportion of the elite of our youth is likely to pass through the great humanities specialist courses - such as Greats and Modern Greats and the Cambridge Triposes-either to the Civil Service or to research in pure science. More of the best of our youth who combine strong character with highquality brain should be encouraged to learn mathematics, physics and chemistry at school, and more of them should be directed to universities where engineering is considered to be a legitimate objective for the very best men.

\section{DOCUMENTATION TECHNIQUES IN THE UNITED STATES}

THE report of the team of European experts on documentation techniques who visited the United States during November and December 1950, under the Economic Co-operation Administration Technical Assistance programme, has now been issued as an example of the contribution of the Organization for European Economic Co-operation to the improvement of European economic efficiency in the sphere of selection, reproduction and dissemination of documents*.

The three chapters of the report describe, first, the libraries and information services visited by the team, documentary reproduction techniques used in the United States, and lastly the use of punched cards and analogous techniques. While the report is largely factual, though highly condensed, each chapter includes a clear statement of the conclusions reached by the team and some recommendations; three, involving action by the Organization for European Economic Recovery, being summarized at the end. The first of these relates to the organization by competent authorities in the United States and in member countries of surveys to provide some comparative data about the degree of utilization of technical and scientific information in industrial organizations. Secondly, the report makes a representation to the United States authorities with the view of increasing the availability of 'unclassified' documents from American defence establishments to non-defence organizations in member countries. Thirdly, the import into Europe of equipment, such as special photographic equipment and special typewriters, which are only available in the United States, should also be facilitated.

For the rest of the report, the team notes the great willingness of libraries and information centres in the United States to provide a service to the technical public, as evidenced, for example, by the late hours which some libraries are open in the evening. Study of the use of Library of Congress catalogue cards is recommended as regards the possibilities both of such methods in other countries and of European co-operation in the production of the cards. The report details at some length the team's reasons for considering that micro-photography does not provide a suitable readable medium for the storage and transmission of scientific and technical information, and advocates the development of 'enlarger-scanners' for preparing enlargements of microfilms of interest. It also considers that each area should have centralized automatic facilities for enlarging microfilms so that such material as is only available on microfilms or, through currency difficulties, can be transmitted more rapidly or simply in that way, may be utilized. There appears to be considerable scope for the use of offset lithography; but progress in this field in Europe is limited by the availability of the special equipment required.

Manually sorted punched cards are more widely used in the United States than in Europe for the documentation of technical and scientific literature, but no special developments are reported. The field punched type of cards is also more widely used, both for mechanical listing operations and to facilitate

- Documentation Techniques in the U.S.A. : Selection, Reproduction, Dissemination. Beport of a Group of European Experts. Pp. 61. (Par's: Organization for European Economte Co-operation; London : H.M. Stationery Office, 1951.) 48. 
selection; and if a standard method of describing series is adopted internationally, extended use of the 'Cardatype' machine in listing serial publications offers an opportunity for co-operation between organizations in different parts of the world in determining the availability of periodicals. The team considers that commercially available selecting machines have achieved nothing that cannot be achieved by traditional methods, although adequate costing data were not obtained and the use of such machines does not eliminate cross-referencing. The future value of the Rapid Selector line of development is also doubtful, but a simplified selector built on the principles of an electronic computor might compete in cost and speed of operation with proposed International Business Machine developments.

\section{MECHANICAL PROPERTIES OF PLASTICS}

$\mathrm{U}$

NDER the title of the "Mechanical Properties of Plastics", the Plastics and Polymer Group of the Society of Chemical Industry organized an allday symposium, held at the Institution of Electrical Engineers, London, on March 7. The considerable interest in the subject was indicated by the fact that some two hundred members and visitors attended, including representatives of the Chemical Engineering Group of the Society. Five papers were presented during the day, and ample time was allocated for the vigorous discussion which followed each contribution.

In a brief introductory summary, Dr. $\mathrm{N}$. J. L. Megson pointed out that since 1939 a revolution has taken place in plastics. The materials are finding increased application to the production of large items having properties not previously considered practicable. Unfortunately, because of a lack of fundamental knowledge, much of the necessary development work has to be done on an empirical basis ; a symposium of the present type was therefore justified, even if it only directed attention to the gaps in our knowledge.

Dr. Megson indicated three main categories in which mechanical testing can be approached: the fundamental approach, which seeks to relate molecular shape and size, or the composition of a heterogeneous material, with mechanical behaviour; the assessment of a material for practical use, by determination of properties by means of carefully selected tests; and the empirical approach, which uses mechanical test procedures to compare one material with another or to lay down standards. $\mathrm{He}$ thought that, of these, the fundamental approach would be expected to prove of greatest interest at a meeting of this character. Nevertheless, this did not mean that the other categories were unimportant, and, in fact, most of the papers naturally covered more than one category in their scope. It was, of course, obvious that the practical utility of a material (the second category) must be of primary importance to the plastics industry.

In the first paper, on the "Physical Evaluation of Small Samples of Plastics", by K. H. C. Bessant, Mrs. M. G. Dilke, C. E. Hollis and J. J. Millane, Mr. Hollis explained that work had been undertaken to permit the evaluation of experimental samples (5-50 gm.). For hard thermoplastics he described tests for impact strengths, softening-points and flow characteristics, while for elastomers (for example, polyvinyl chloride) he dealt with tensile strength and elongation at break, British Standard hardness, brittle temperatures, resilience and plasticizer loss. With suitable precautions, all these can be carried out with appropriate modifications of existing methods. Reproducibility is sufficient for making significant comparisons between laboratory samples. This paper provoked questions about the shape and size of test pieces and on plasticizer volatility, and discussion also took place on the speed of testing in dilatometric determinations and on the $T m$ curves for polystyrene, which become one continuous curve at equilibrium. Mr. Hollis, in reply to the last point, mentioned the investigations of Spencer and lsoyer, and of Mark, which are not in agreement with those of Bekkedahl; he said that Mr. Millane and Mrs. Maclaren are shortly going to publish a paper which supports the first workers' contention that a straightline graph is produced at equilibrium.

In a joint study of the "Interpretation of Mechanical Tests of Plastics", by C. G. Evans and H. W. Hall, the authors explained that they were concerned with the development of materials suitable for the production of aircraft structures. In particular, they referred to asbestos-reinforced phenolic resin compositions, moulded under very low pressures. They pointed out that the most important properties are strength and stiffness in tension, compression and shear, together with toughness, which is connected to some extent with impact strength. They explained the problem of translating laboratory tests into terms which will enable engineers to use the materials efficiently in practice. Mr. Hall stressed the difficulties associated with determinations of impact strength, and made a strong plea that tensile impact should replace existing methods, illustrating his remarks with information obtained from an American source. The work by the authors has involved examination of the effects caused by various reinforcing fillers with a variety of resins. The discussion on this paper covered a wide field, including the importance of moisture content in laminating material, the significance of good adhesion between filler and resin (and therefore the influence of type of asbestos on strengths, since different grades show varying adhesion), the size of test pieces and the influence of surface finish, the calculation of theoretical strengths of moulded compositions, the importance of rate of loading in testing, the possibility of developing improved sizes for glass fabrics with the idea of improving resin adhesion, the value of tensile-impact testing, and the influence of fibre length on ultimate strengths of mouldings.

The next speaker, Dr. E. A. W. Hoff, in a study of "Some Mechanical Properties of 'Perspex'", showed plainly how important is the fundamental approach of the first category mentioned by Dr. Megson. After considering the nature of polymer molecules, their entanglement and their mutual reactions, together with temperature effects, Dr. Hoff pointed out that it is unwise to take over existing metal-testing techniques with the expectation of obtaining results useful in the field of plastics. $\mathrm{He}$ illustrated his point by referring to the relations between molecular structure, on one hand, and fatigue results, compression and tensile testing and static loading strengths, on the other. Finally, in agreement with Mr. Hall, he emphasized the difficulty of interpreting satisfactorily the results of 